\title{
GRAPHIC COMMUNICATIONS IN THE CONTEXT OF NEPAL
}

\section{JITENDRA MAN RAJBHANDARI}

\begin{abstract}
Graphic communication, a powerful tool for conveying information through visual aids has undergone a radical change since its early application by cave artists of Paleolithic age. With the development of print technology, both the scope and significance of graphic technology have been expanding. In the context of Nepal, graphic communication has received an attention since the advent of printing press. Several artists, illustrators and graphic designers have made great contributions on the development of this form of Applied Arts. Since the last few years the Fine Arts institutions in Nepal have been introducing Graphic Communications into their curriculum which is sure to uplift the quality of graphic design in promotion of the products and services in the Nepali market.
\end{abstract}

Graphics have been powerful tools for visualizing and shaping our ideas. Graphics are images that appeal the human sense when they reach the brain through the eye. Graphic Communication, a mode of communication through visual aids, has already redefined our understanding of communication. Graphic Communication is, in fact, a translation of ideas, stories and concepts into a visual format. In Italian designer Massimo Vignelli's words, it is the "communication of information in appropriate visual manner." Graphic Communication is all about sharing ideas both creatively and effectively. This short article intends to trace a brief history of
Graphic Communications with special reference of Nepal.

The origin of Graphic

Communications dates back to prehistoric era of cavemen some 30,000 years ago. Early men, particularly in Europe, began drawing on walls of caves of Chauvet, Lascaux, and Alta Mira. These cave paintings were created with the use of minerals and charcoal utilizing brushes, hands, and hollowed reeds in which the painter would spray color from their mouth. Although it is still a matter of debate whether they were made for religious purposes or demonstrating hunting techniques, or recording of events, the one purpose of these certainly is a means of visual human 


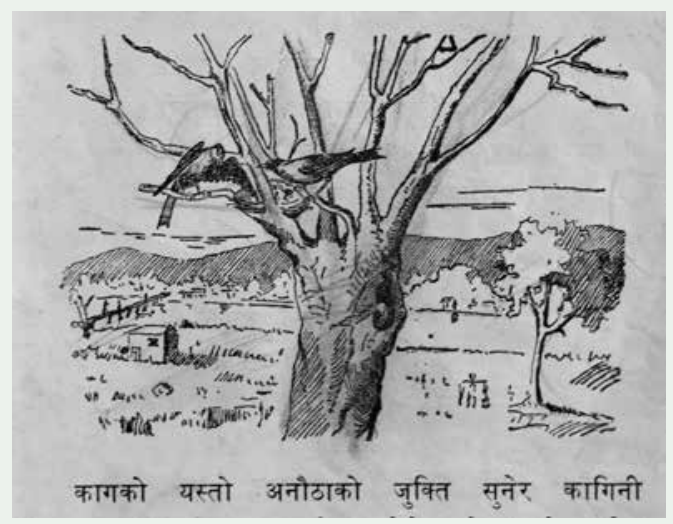

An early example of book illustration done by Tej Bahadur Chitrakar for 'Nepali Prabeshika - 1', Published by McMillan and Co. Ltd, Calcutta. 1949.

communication. Later Sumerians created one of the first written languages using symbols that eventually developed into formal style writing as we know today.

The invention of printing press was yet another turning point in Graphic Communications. In 1439 Johannes Gutenberg brought moveable type to Europe opening up literature (and literacy) to the masses and making it affordable. With the advent of the printing press humanity was able to recreate text, art and design on a massive scale, and for relatively cheap price. It is noteworthy that the Gutenberg press paved the way for more commercial uses of design, which ushered to the era of Graphic Design. People soon noticed how such visuals could affect shopping behaviors and increase profits. Thus modern graphic design really began after the invention of the printing press.
Technological advancements have opened up tons of possibilities in Graphic Communications. The desktop computers and digital software have made representation of ideas and information visually possible in many more ways. With the boom of media technology, Graphic Communications have become an inseparable part of mass media.

In the context of Nepal too, graphic designing turned an essential requirement with the entry of printing presses. Before that most of Nepali books used to be printed in Benaras. The value of Graphic Communications was first manifested with the use of illustrations in those books. Ratna Pustak Bhandar was probably the first

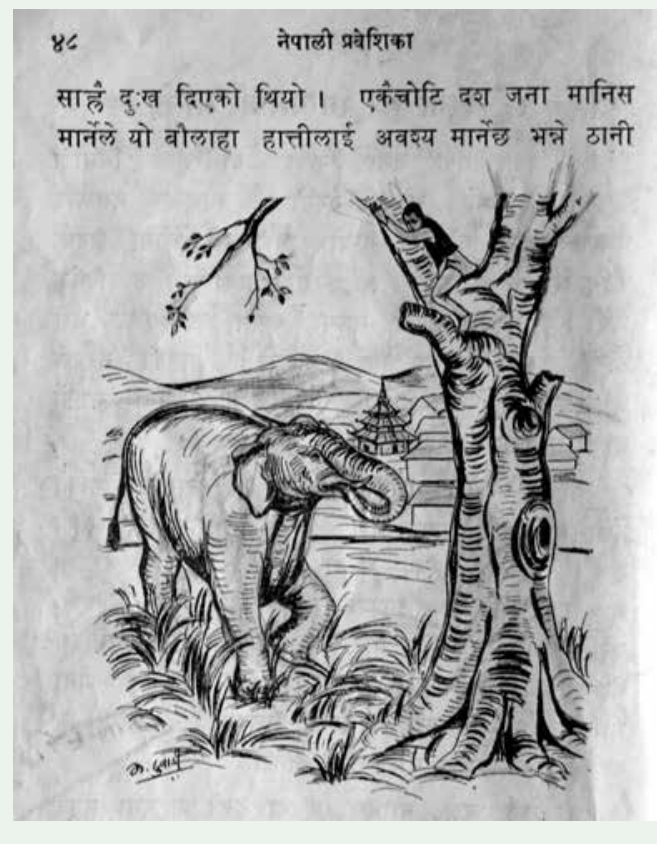

An early example of book illustration done by Keshav Duwadi for 'Nepali Prabeshika - 1', Published by McMillan and Co. Ltd, Calcutta. 1949. 


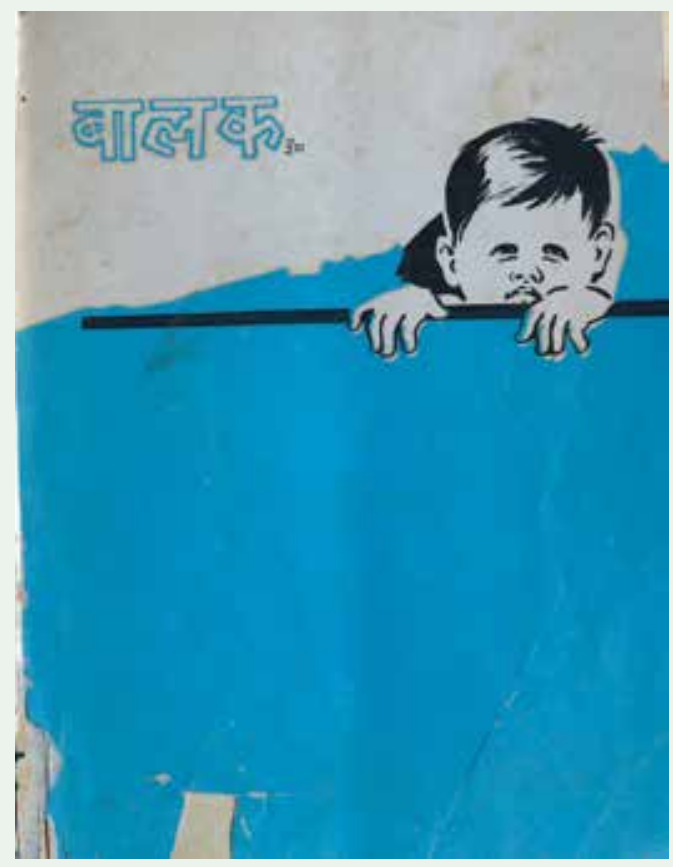

A cover design done by Dil Bahadur Chitrakar for 'Baalak' - a children magazine, published jointly by Janak Education Materials Center and Nepal Children Organization, 1971.

Nepali publisher to institutionalize book publishing business. In those early days, Keshav Duwadi appeared as the pioneer illustrator in Nepali publications. A graduate from Sir J.J. School of Arts, Mumbai, Duwadi is often credited for his contribution to introduce illustrations in Nepali books. His illustrations on popular Nepali religious text of Swasthaani Brata Kathaa can be regarded as one of best instances of early illustrations which visualize the Hindu gods and goddesses in entirely Nepali attire.

After the promulgation of New Education Plan in the year 1971, a wave of new textbooks hit the education sector. Those school

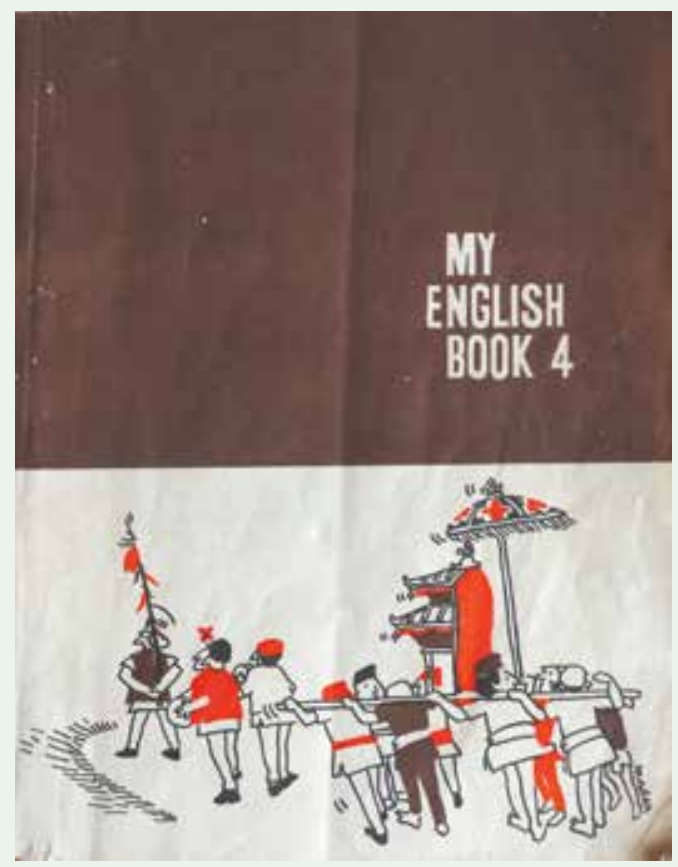

A cover design with modern approach done by Madan Chitrakar for 'My English Book 4', published by Janak Education Materials Center, 1974.

textbooks, mostly printed at Janak Education Materials Center, Sanothimi gave a new look to Nepali textbooks with brand new layouts and vivid illustrations. Madan Chitrakar, Dil Bahadur Chirakar, and Manuj Babu Mishra were the most prolific illustrators in this era. Apart from that Tek Bir Mukhiya's cover designs in the most of books published by Sajha Prakashan and K.K. Karmachaya's stamp designs are also the noteworthy works of Nepali Graphic Communications.

Coming to 80s decade, emergence of offset printing technology replaced the letter press and zinc blocks from Nepal. Jor Ganesh Press, Sahayogi 


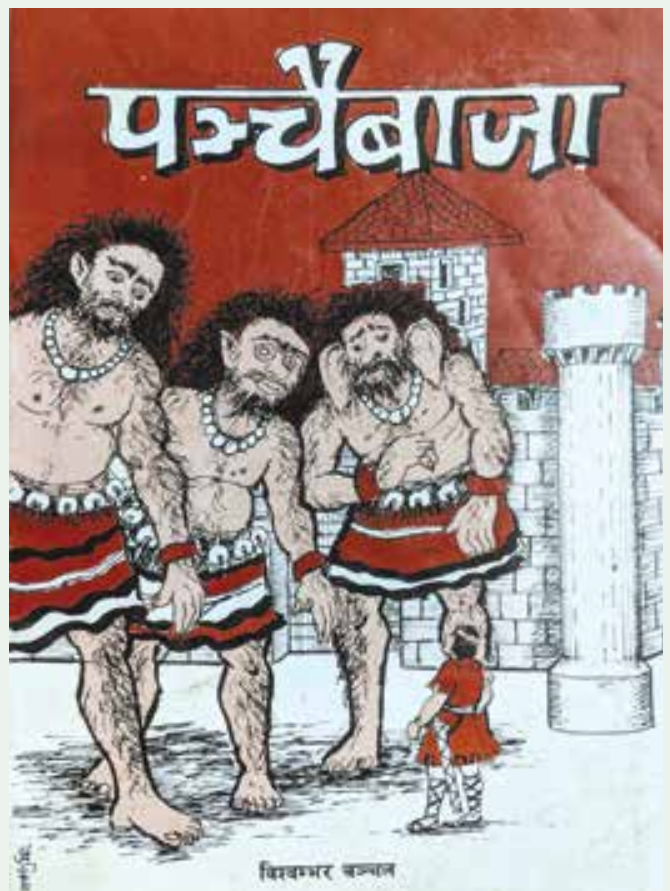

A cover design done by Tek Bir Mukhiya for a book written by Bishwombhar Chanchal, published by Saajha Prakashan, 1973.

Press, and Modern Press together with government owned Gorkhapatra press opened up new vistas of graphic designing for Nepali artists. Multi color art work designs saw a boom with the political change of 1990. The Ministry of Health, Ministry of Education and UNICEF brought out various materials with lots of graphic contents and development illustrations. This period saw the rise of the outstanding illustrators like Durga Baral, Madan Chitrakar, K. K. Karmacharya, Ujjwol Kundan Jyapoo, Sharad Ranjit and others. They were followed by the professional graphic communicators like Ashok Man Singh, Mohan Khadka and others.
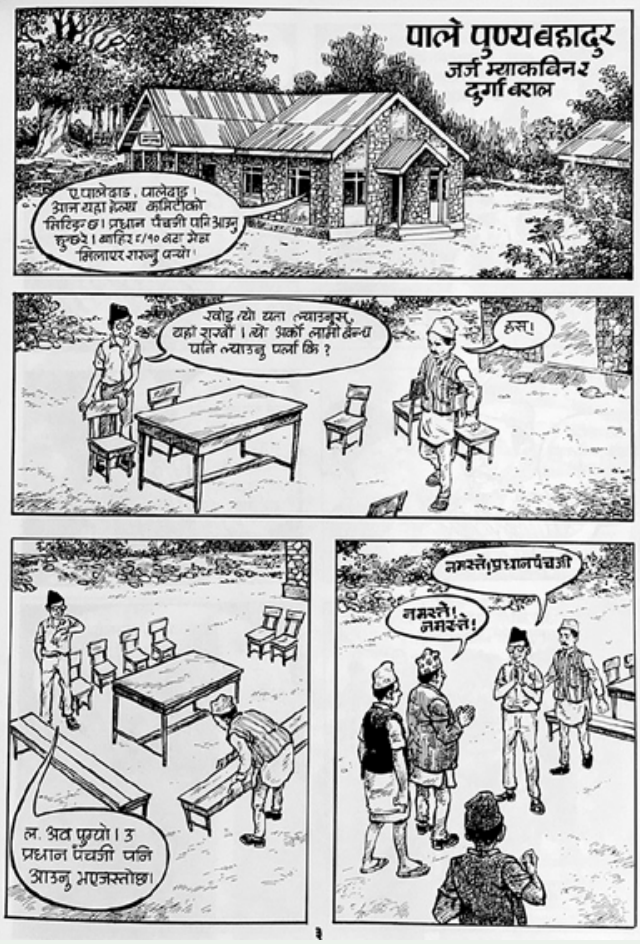

An illustration done by Durga Baral for 'Nava Drishya' - a publication for neo-literates, published by UNICEF, 1987.

Prominent artist Madan Chitrakar is the first Nepali artist to receive formal degree in Applied Arts. The graduate from Sir J. J. School of Arts, Mumbai, Chitrakar is also the pioneer figure to start teaching Graphic Communications in the Nepali art colleges. Moreover, his illustrations on the series of the textbook entitled My English Book are still considered a milestone in Nepali school textbooks. He says, "Graphic Communications is basically a form of Applied Arts meant for human consumption. Here art is 'applied' with certain motive. It encompasses anything from logo designing, press campaign, product 


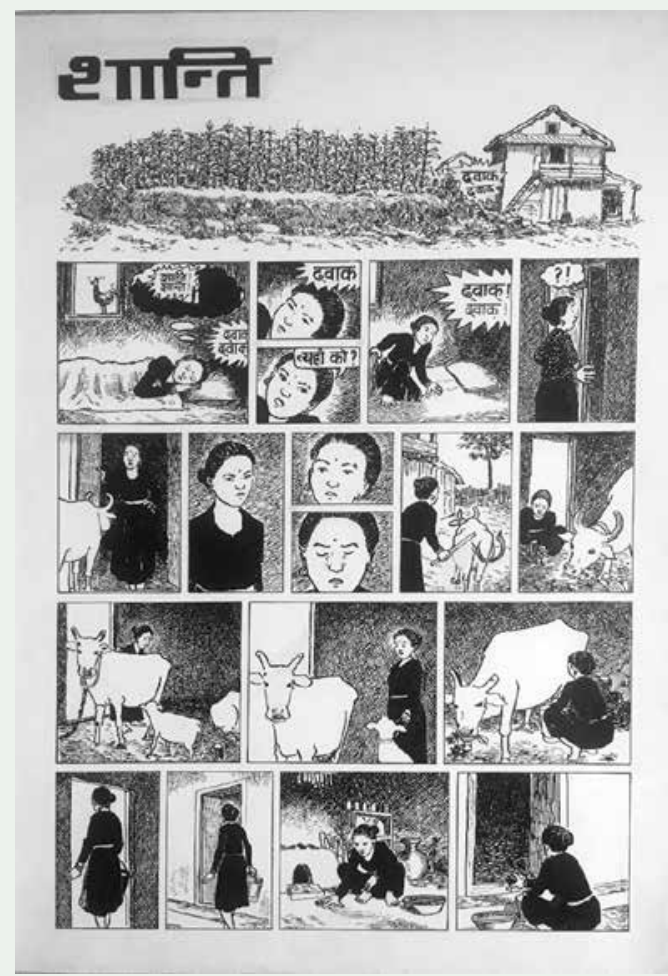

An illustration done by Sharad Ranjit for 'Nava Drishya' - a publication for neo-literates, published by UNICEF, 1987.

promotion, branding to developing corporate identity."

Another instructor Bijaya Maharjan, who represents the young generation of Graphic Communicators in Nepal, opines that the field of Graphic Communications is diverse. He sees lots of distinctions between Fine Arts and Applied Arts. "Fine Arts is a form of self expression where as applied art is a purposeful art. Within it, label, poster and brochure designing, photography and illustrations are all included," Maharjan says.

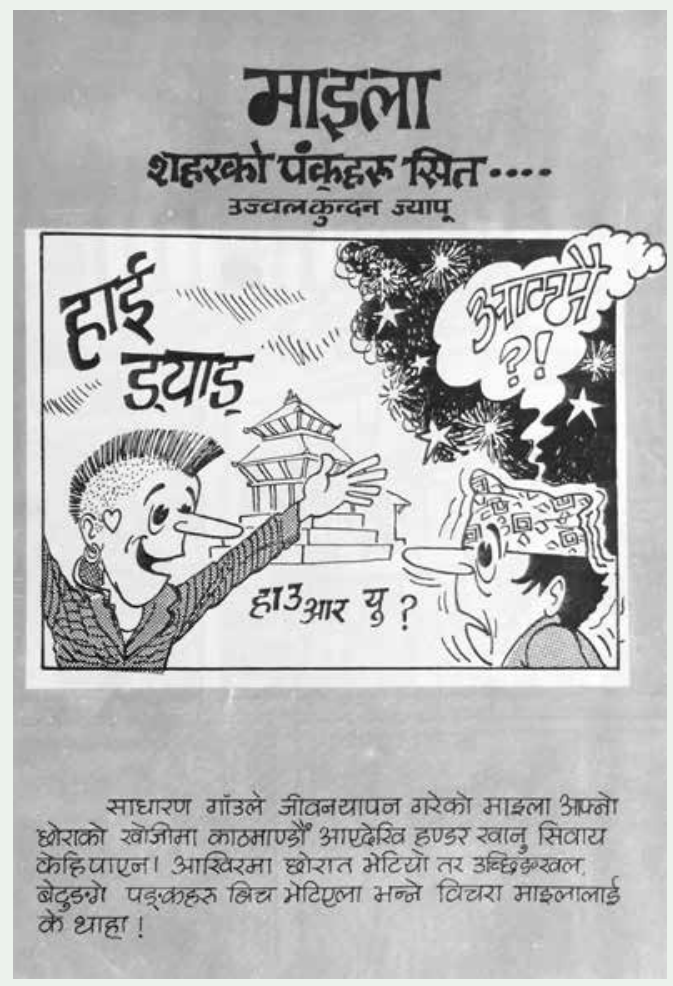

An illustration done by Ujjwol Kundan Jyapoo for 'Nava Drishya' - a publication for neo-literates, published by UNICEF, 1987.

\section{Graphic Communications in Nepali Art Education}

Regardless of its importance and the relevance however, Graphic Communications as a formal course of studies, has proven a late comer in Nepali Art education system. Speaking honestly, the arrival of this genre is a recent phenomenon - it is due to various reasons including the sheer ignorance of the part of concerned stake holders.

The formal beginning was made in the country as late as beginning of the 21st century by Kathmandu University, 


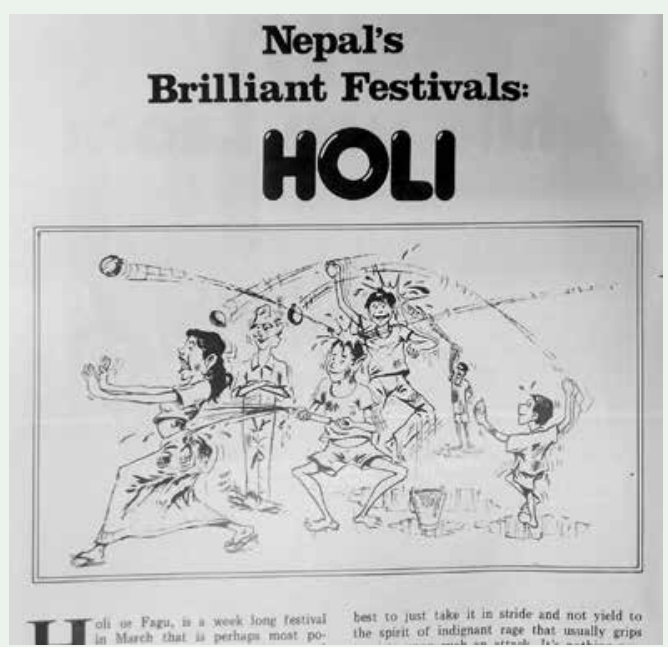

An illustration done by Mohan Khadka for 'Nepal Traveller' - a magazine on travel and tourism, published by Ramashesh Pd. Shah, 1984.

Center for Art and Design with a provision of Bachelors' Degree in Fine Arts as an independent course of Studies in Graphic Communications. The primary credit must be attributed to the two individuals Aiden Warlow, an educationist from the Great Britain and Sujan Chitrakar, the academic co-ordinator of the Center. In association with Madan Chitrakar, a historic beginning was made with designing the first ever curriculum of the subject and the first commencing of the first BFA Studies in Graphic Communications was made. The historic beginning was made initially in a very modest class room with spartan facilities needed in the studies. The rest is history.

Realizing the importance soon after, Tribhuvan University (TU), the Faculty of Humanities and Social Sciences followed suit and

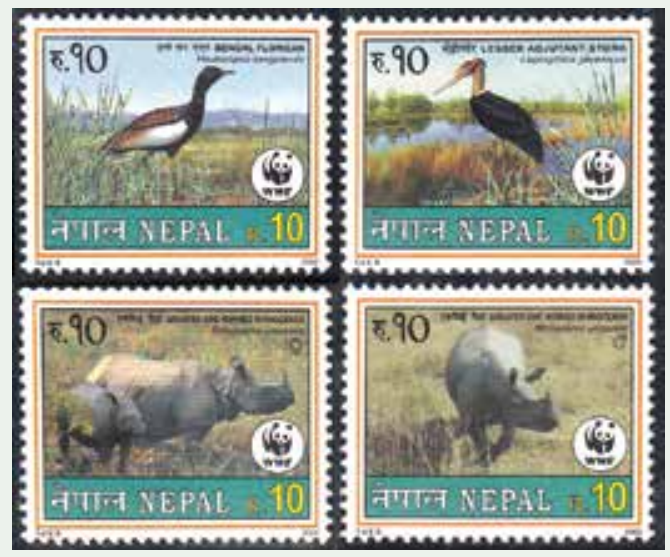

Stamps designed by K. K. Karmacharya for the Department of Postal Service.

introduced a four years studies of Bachelors Degree (BFA) in Graphic Communications. Accordingly, all the colleges under the aegis of TU commenced the formal studies under their academic programs. And lately, the achievements made by the graduates of the Sirjana College of Fine Arts in the genre, continue to prove phenomenal - with each successful graduates contributing brilliantly from their respective positions.

The TU course aims to impart the knowledge and skills with particular focus in the following areas:

- Understanding of space and the importance of space management

- Familiarity with the fundamentals of design

- Practice in print media, e.g. corporate identity, press advertisements and illustration 

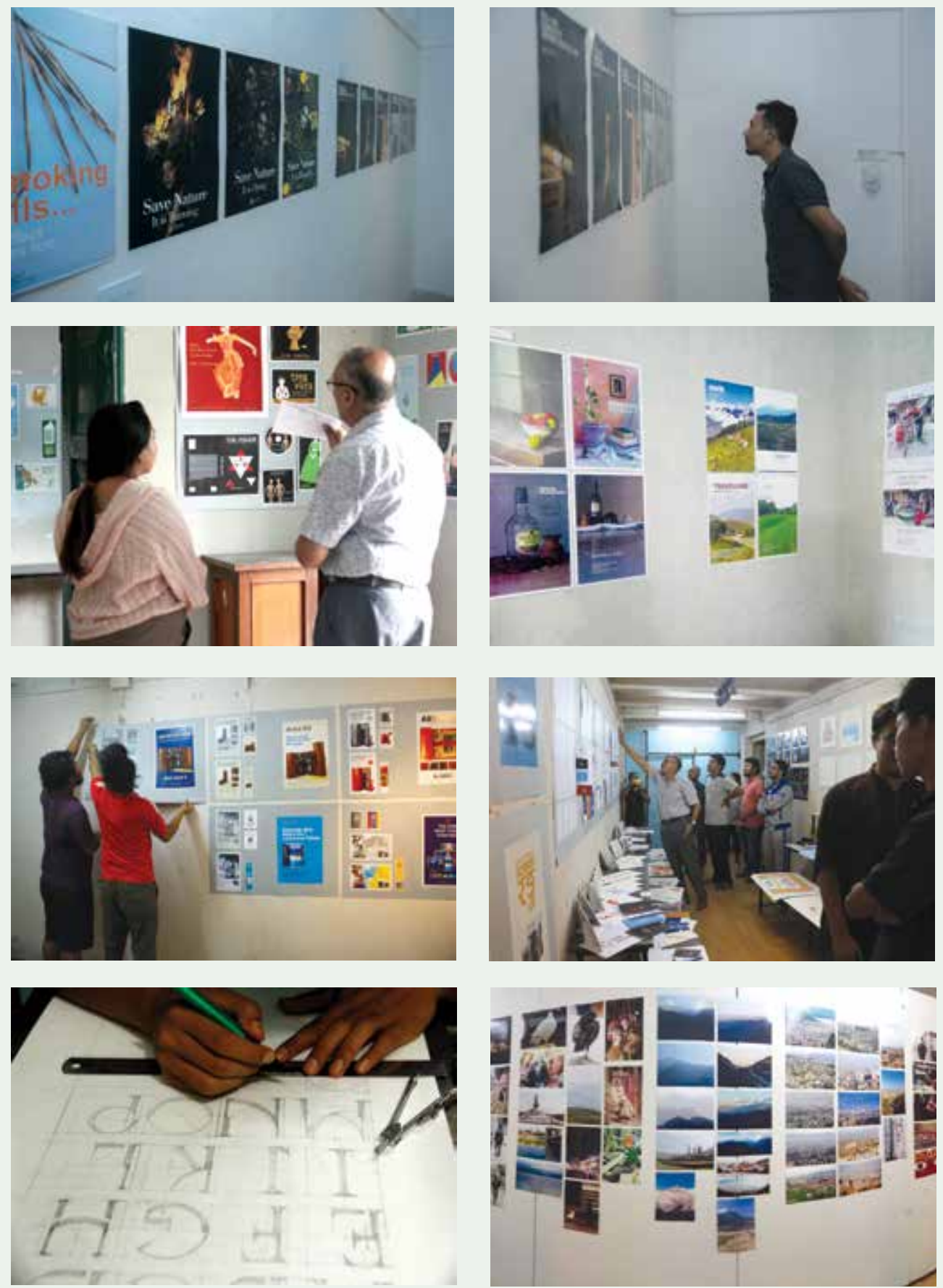

Some glimpes of the activities carried out by the students of BFA, Graphic Communications in Sirjana College of Fine Arts. 
- Understanding digital tools, e.g. computer software and photography as means of graphic design

From this short analysis of the university curriculum of Graphic Communications, it is clear that this course is basically focused on the pragmatic application of arts for utilitarian purpose. Hence, the Graphic Communications studies are sure to yield much more beneficial outcomes in developing country like Nepal.

To sum up, the area of Graphic Communications and Applied Arts is endless. They have been emerging as powerful domain of mainstream art and art education. The involvement of talented and creative young artists in this field heralds indeed an optimistic future of Nepali Applied Arts. The growing awareness of corporate and non corporate sectors about the importance of Graphic Communications in promotion, branding of their products and services is also sure to take Graphic Communications to a new commercial height in the days to come.

\section{Works Cited}

Chitrakar, Madan. Personal interview. 10 Sep. 2018.

Cramsie, Patrick. The Story of Graphic Design. British Library, 2010.

Ekilson, Stephen J. Graphic Design: A New History. Yale UP, 2012.

Maharjan, Bijaya. Personal interview. 12 Sep. 2018.
Onta, Pratyoush. Mass Media in Post-1990 Nepal. Martin Chautari, 2006.

Tribhuvan University. Curriculum of BFA Four Years Bachelor in Graphic Communications, 2014.

Vignelli, Massimo. The Vignelli Cannon. Lars Muller, 2015.

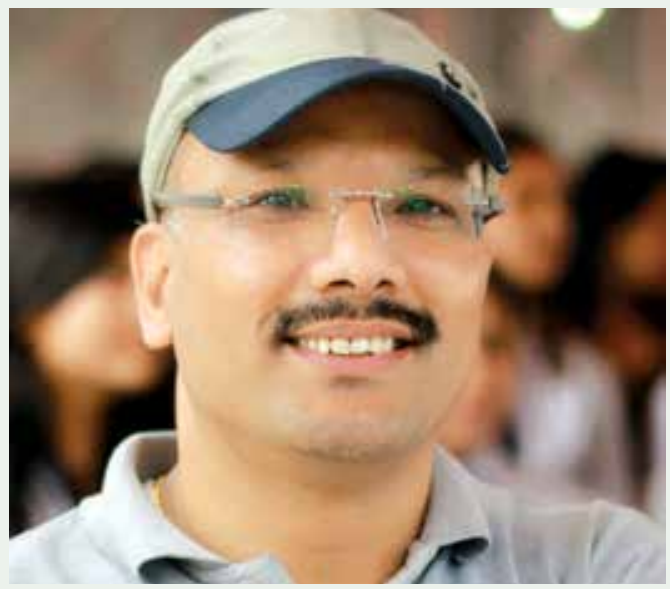

Jitendra Man Rajbhandari

Jitendra Man Rajbhandari is an Associate Professor of English in Tribhuvan University. He has been teaching English Literature and Business Communication for about 25 years. Presently, he is associated with Saraswati Multiple Campus as the Head of the English Department. 